\title{
Cloud Computing Adoption at Higher Education Institutions in Developing Countries: A Qualitative Investigation of Main Enablers and Barriers
}

\author{
M. Odeh, A. Garcia-Perez, and K. Warwick
}

\begin{abstract}
The extensive use of cloud computing is changing the way of dealing with information and communication technology. Cloud computing has created a new concept to deal with software services and hardware infrastructure. Some benefits are immediate; for instance, to allow students to share their information easily and to discover new experiences of the education system. However, despite the comprehensive literature, there is still limited studies related to the applied factors that influence the adoption of cloud technology at higher education institutions. Such limitations in the literature arise clearly in developing countries. This paper attempts to enhance the understanding of related factors affecting the adoption of cloud computing in the educational context of developing nations. A fieldwork study for collecting data has been conducted at higher education institutions in the kingdom of Jordan. This study applied an interpretive paradigm with a qualitative research method to investigate the main enablers of and barriers to cloud computing adoption at the universities in developing countries in general and in the case of Jordan in particular.
\end{abstract}

Index Terms-Cloud computing, higher education, developing countries, enabler factors, barriers factors, qualitative study, NVIVO.

\section{INTRODUCTION}

Cloud computing is a new paradigm, which provides applications and services that can be accessed through the internet with the ability to share, managing and storing data, which is physically hosted on remote servers instead of using in-house resources or personal machines [1]. Cloud computing provides advances in technology, such as high processing speed, distributed and grid computing availability, and high storage capacity. In addition, through its use, the common problems of limited computational power and limited physical data storage can be ameliorated [2]. This synthesis integrates hardware, software, networks, and storage options to deliver shared computing solutions in which applications and other services would be provided over the Internet [3].

Cloud computing has four deployment models: public, private, community, and hybrid. According to Chou [4], the public cloud is considered to be the most popular model in cloud computing. Service providers such as Google, Amazon, and IBM offer inexpensive or even free Cloud

Manuscript received October 24, 2016; revised December 14, 2016.

The authors are with the Coventry University, Priory St, Coventry CV1 5FB, United Kingdom (e-mail: Odehm2@uni.coventry.ac.uk, Alexeis.garcia-perez@coventry.ac.uk,Kevin.warwick@coventry.ac.uk). computing services to the public [5]. However, despite the low cost and broad availability of public cloud services, it is widely believed that this cloud model has less security protection compared with other models [2], [4]-[7]. In addition, the shared resources pool in public cloud computing model has physical capacity limitations as well as low processing performance unless the customer agrees to pay more for a premium edition [8].

In the public cloud model, the service provider would not enable the client to control the physical resources at any level. Therefore, such limitations in control from the same physical servers might allow other clients to access an organisation's critical data unintentionally [8]. In quite the opposite of the public cloud nature, the private cloud model enables the client to maintain control over the physical cloud resources. In the private cloud model, the client leases or owns control of the cloud infrastructure. This infrastructure is operated solely for a specific client by a cloud computing service provider [9]. However, the cost of adopting a private cloud model is obviously more expensive than the public cloud [10]. Integration between public and private cloud models usually offer the benefits of these two different models as well as enabling the users to avoid the limitations of these two models [9]. Such integration is called a hybrid cloud [2]. Finally, the community cloud model enables organizations that have the same concerns such as security, mission and policy to share the same cloud infrastructure [9].

In addition, cloud computing could also be categorized according to service models such as software as a service (SaaS), platform as a service (PaaS), hardware as a service (HaaS), infrastructure as a service (IaaS).

However, universities that are becoming increasingly complex environments need to take certain measures with regard to cloud computing. These measures including the introduction of web-based student services without a proportionate growth in the personal budget, as well as implementing software and hardware. Moreover, they aim to decrease total costs while managing the highest level of privacy, updating security, and ensuring the capacity to accommodate a growing number of devices.

\section{Cloud Computing AT Universities IN DEVEloped COUNTRIES}

Cloud computing has become common in higher education and universities [11]. For example, many colleges and universities in Commonwealth countries introduced a collaborative system named Virginia Virtual Computing Lab, 
which enabled these colleges and universities to reduce their IT expenses by eliminating the requirements of software updating and licensing [12]. One study by Mircea \& Andreescu [13] argued that about $70 \%$ of IT leaders in higher education recommended cloud computing over traditional computer technologies, stating that improving IT services is the most crucial factor in their decision. In addition, it is estimated that using cloud computing technology at any institution may reduce the total operational cost by 25 to 30 percent [14].

Cloud computing technology provides a serious step across the educational industry and an important opportunity to improve structural efficiency, stimulate innovation, decrease spending on technology, and increase agility [15], 16]. Furthermore, cloud computing promises to provide almost unlimited computational power at low cost [7]. Such cloud computing benefits may solve the challenge of resource limitations and the lack of advanced technology availability in developing countries [17].

The importance of cloud computing in higher education has increased rapidly with the passage of time, and it is obvious that its use and its importance will continue to grow in the future [13], [18]. This is mainly due to its benefits in teaching and learning, among other aspects [4].

\section{Cloud Computing AT Universities IN DEVEloping COUNTRIES}

According to Stein et al. [5], cloud computing can increase education efficiency, improve quality, and reduce the overall IT costs. For example, several education institutions in East Africa (e.g. the University of Nairobi, the Kigali Institute for Education, and Kenyan Methodist University) have collaborated with Google to gain significant benefits from Google cloud applications for both students and lectures [2].

Furthermore, in Ethiopia, Microsoft has supported education institutions by rolling out 250,000 laptops for lectures, which all run Windows Azure, which is mainly based on the platform as a service [18]. Windows Azure is an operating system that depends on cloud computing technology, and lectures in Ethiopia use it to upload and download curriculum and securely transfer students' records into the education system. This process prevents the education institutions in Ethiopia from having to invest heavily in datacenters as well as hardware and software for connecting this huge number of transactions.

In a large longitudinal study, Shirazi, Gholami, \& Higón [19] investigated the impact of information technology on the economy of 11 countries in the Middle East (Jordan, Oman, Yemen, Saudi Arabia, Qatar, Syria, United Arab Emirates, Bahrain, Iran, Kuwait and Lebanon). The findings of this study argued that there is a positive and strong link between economic growth and the utilization of ICT. In addition, it showed that countries with higher education attainment such as Jordan, Kuwait and Bahrain were able to gain more benefits from ICT, whereas other countries such as Iran and Syria were less advantaged by ICT because of government constraints and policies, which prevent the growth of ICT infrastructure.

In their excellent study of cloud computing adoption in
Oman, Sharma, Al-Badi, Govindaluri, \& Al-Kharusi [20] were able to show that job opportunities have a strong positive relationship with the adoption of cloud computing at the individual level. The same study has concluded that other factors such as perceived usefulness, self-efficacy and trust positively influence the adoption of cloud computing technology.

According to Truong, Pham, Thoai, \& Dustdar [17], education institutions in developing countries mainly focus on teaching and learning activities. Although some universities in developing countries are considered as research-oriented institutions, these institutions are smaller than teaching-oriented universities. The same authors argued that universities in developing countries face many challenges, which can be characterized as following:

- Universities in developing countries suffer from limited resources compared with population rate. Therefore, students also experience a high level of competition between each other for securing a seat in these universities.

- High-quality resources are not available due to cost. As a result, technology resources in developing countries universities cannot process complicated and advanced scientific projects.

- The Laboratory facilities are not available out of class hours. Therefore, the students are restricted in when they can use university facilities.

- The lack of communication and knowledge sharing between lectures and students outside the classroom.

In theory, cloud-computing resources can be used in the developing countries with the same approach as in developed countries [21]. However, the educational environment, culture, and resources are different. For example, utilizing cloud computing services effectively needs well-prepared infrastructure such as internet upload and download speed, which still not available in most of developing countries [2].

In developing countries, there are several barriers to the adoption of cloud computing in universities. These barriers include the cost and payment method [17], lack of electric power stability and poor broadband infrastructure [22], lack of awareness [23], security and privacy concerns [21], and lack of cloud computing technical experts [17].

- Cost and payment method: even though cloud computing reduces the cost of IT through reducing the physical infrastructure, it is still expensive for universities in developing countries. In addition, cloud computing service providers usually accept electronic payment by credit or debit cards. This payment method is a problem in developing countries, which still prefer traditional payment methods rather than online banking because of limitations in online banking services. Therefore, the lack of online payment services may hinder the adoption of cloud computing in higher education institutions.

- Lack of electric power stability and poor broadband infrastructure: In many developing countries such as India, Africa, Jordan, Syria, and Iraq the electricity can shut down unexpectedly from the power supplier. Such instability of electricity may destroy the process of upload and download, especially if there is a large amount of data that depends on automatic tasks (e.g. schedule backup of 
student's records).

- Lack of awareness: According to Rogers [24], the first stage in new technology adoption is awareness about this technology. In a study which set out to determine the factors of cloud computing adoption at universities in developing countries, Sabi et al. [21] found that the awareness of cloud computing benefits is strongly and positively correlated with cloud computing adoption. This study suggests that an awareness of the benefits of cloud computing is the main factor that affects the decision of cloud computing adoption at universities in developing countries.

In the same vein, Truong et al. [17] argued that it is fundamental to increase the awareness in developing countries about the main benefits and challenges of cloud computing, for example by displaying the best practice from education institutions in developed countries, which benefit from the adoption of cloud computing. However, the education context of developing countries is quite different from the developed countries' education sector (e.g. culture, attitude towards technology, individual behavior, and resistance to new technology).

- Security and privacy concern: A recent study by Alkhater, Wills, \& Walters [25] which investigated the intention to adopt cloud computing in Saudi Arabia noted that security and privacy were the main concerns in adopting cloud computing services. However, the main weakness of the study is the failure to address how these factors prevent the adoption of cloud services in Saudi Arabia context. Furthermore, another weakness is that the study fails to discover new factors that affect the cloud computing adoption in Saudi Arabia. Unfortunately, the author offers no explanation of how these factors are considered barriers or enablers to cloud computing adoption.

\section{Methodological APPROACH}

This study requires in-depth analysis to understand the current and expected future situation. Therefore, the researcher will endeavor to adopt a qualitative approach, because this will provide a better understanding of the situation in real life, as well as investigate the main factors affecting the adoption of cloud computing. The data collection in this research comes from semi-structured interviews with professors from the Jordanian universities as well as experts in cloud computing technology.

The analysis process of collected data has been conducted using Computer Assisted Qualitative Data Analysis (CAQDA). Accordingly, this research employed Nvivo software, which is considered to be one of the most useful software tools for qualitative data analysis. Using Nvivo software enables the researcher to code the collected data as well as to link and create relationships between codes [26]. In addition, it helps to reshape, reorganize, and compare the coding nodes easily. Almost all interviewees were experts in cloud computing technology. Table I shows the interviewees' profiles. The study attempts to cover both academic and technical perspectives. Therefore, the participants have been categorized into academic professors (P), and technical experts (TE). Accordingly, there were 10 participants for the in-depth semi-structured interviews, five professors from a computer science school, an engineering school, and an information system department and five technical experts (e.g. IT manager, team leader, and senior technical engineer).

\begin{tabular}{|c|c|c|c|}
\hline Code & Title & Professionality & $\begin{array}{l}\text { Years of } \\
\text { experience }\end{array}$ \\
\hline $\mathrm{P} 1$ & $\begin{array}{l}\text { Head of computer } \\
\text { science school }\end{array}$ & $\begin{array}{l}\text { Professor in cloud } \\
\text { computing (Database } \\
\text { expert) }\end{array}$ & 22 Years \\
\hline $\mathrm{P} 2$ & $\begin{array}{l}\text { Dean of } \\
\text { management } \\
\text { information } \\
\text { systems (MIS) } \\
\text { departments } \\
\end{array}$ & $\begin{array}{l}\text { Professor in } \\
\text { (Management } \\
\text { information systems) }\end{array}$ & 19 Years \\
\hline P3 & Senior lecturer & $\begin{array}{l}\text { Associate professor } \\
\text { of computer science }\end{array}$ & 14 Years \\
\hline $\mathrm{P} 4$ & Senior lecturer & $\begin{array}{l}\text { Associate professor in } \\
\text { computer engineering } \\
\text { school }\end{array}$ & 16 Years \\
\hline $\mathrm{P} 5$ & $\begin{array}{l}\text { Head of computer } \\
\text { engineering }\end{array}$ & $\begin{array}{l}\text { Professor in computer } \\
\text { engineering school }\end{array}$ & 26 Years \\
\hline TE6 & $\begin{array}{l}\text { Chief technology } \\
\text { officer }\end{array}$ & $\begin{array}{l}\text { Professional in } 3 \mathrm{D} \\
\text { programming and } \\
\text { simulation } \\
\text { And expert in cloud } \\
\text { computing platforms }\end{array}$ & 11 Years \\
\hline TE7 & Senior engineer & $\begin{array}{l}\text { Technical support } \\
\text { engineer in virtual } \\
\text { machine } \\
\text { Microsoft certified } \\
\text { engineer }\end{array}$ & 8 Years \\
\hline TE8 & IT manager & $\begin{array}{l}\text { Educational } \\
\text { applications and } \\
\text { Elearning. Graid } \\
\text { computing, big data, } \\
\text { and Java wireless } \\
\text { applications. }\end{array}$ & 13 Years \\
\hline TE9 & IT manager & $\begin{array}{l}\text { Educational } \\
\text { applications expert, } \\
\text { cloud computing } \\
\text { expert, and } 3^{\text {rd }} \text { line } \\
\text { technical engineer. }\end{array}$ & 9 years \\
\hline TE10 & $\begin{array}{l}\text { Chief executive } \\
\text { officer (CEO) }\end{array}$ & $\begin{array}{l}\text { 3D applications and } \\
\text { virtual reality, image } \\
\text { processing expert. } \\
\text { Senior developer in } \\
\text { educational } \\
\text { applications, } \\
\text { simulations programs, } \\
\text { and virtual machines } \\
\text { languages. }\end{array}$ & 17 Years \\
\hline
\end{tabular}

\section{Study RESUlts: MAIN ENABLERS AND BARRIERS OF ClOUd COMPUTING ADOPTION AT HIGHER EDUCATION INSTITUTIONS}

This section provides the findings of this study. The findings have been categorized according to the following factors: security and privacy, the resistance of new technology, cost effectiveness, compatibility, easy to use, centralization, management support, and knowledge sharing.

Fig. 1 shows the findings from this study regarding the main factors affecting the adoption of cloud computing at universities in developing countries, using Nvivo map analysis.

\section{A. Security and Privacy}

The findings show that security and privacy concerns are considered to be the most important issue affecting the 
adoption of cloud computing at higher education institutions, as one of the professors (P2) in management information systems explained:

"Privacy is the main concern in using cloud computing. A considerable amount of publications agreed that privacy and security are the main issues in cloud computing and we cannot ignore this fact".

In the same context, another professor (P1) added that:

"Although there are several solutions such as data encryption, we believe that the service providers can access the customer data. As many governments around the world have polices and regulations that enable them to access the companies and service providers customer data if needed for security purposes".

In brief, the finding revealed that security and privacy is one of the main barriers that negatively affects the adoption of cloud computing in higher educational institutions.

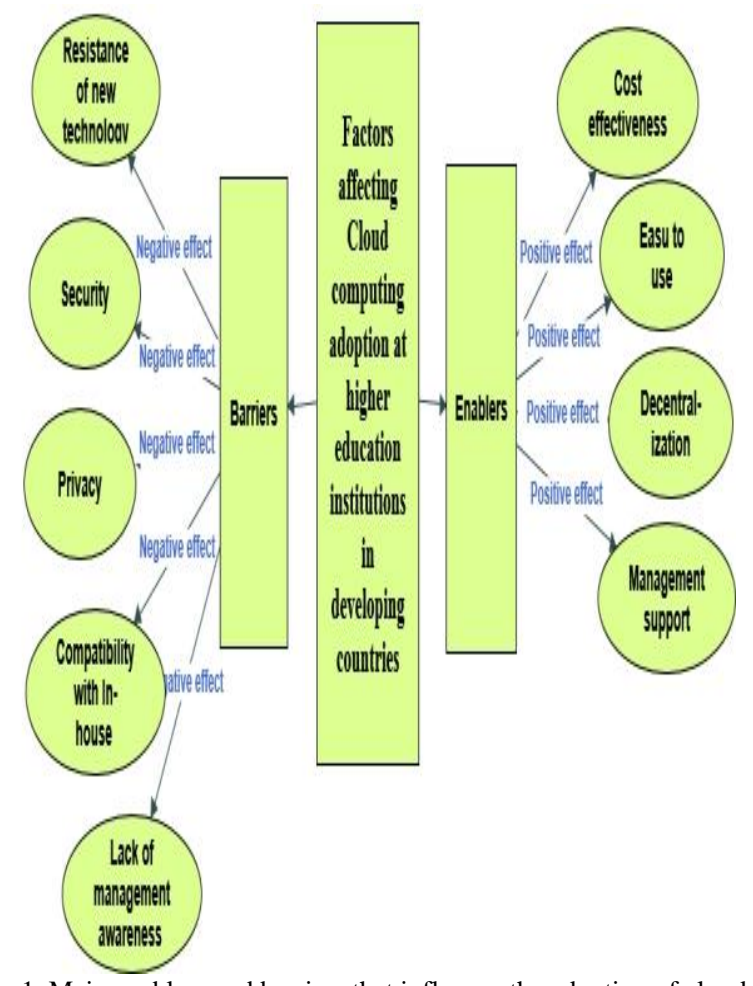

Fig. 1. Main enablers and barriers that influnces the adoption of cloud compuitng at higher education institutions in Jordan: findings from the fieldwork.

\section{B. Resistance of New Technology}

The adoption of innovation technologies such as cloud computing at higher education in developing countries is a transformation from old and traditional learning methods to new ones, which means a new learning and teaching environment for lecturers and students. One of the IT managers (TE8) stated that:

"In the current situation, the adoption of cloud computing would not be a success. It is clear that there is a strong resistance by students and lecturers to use any new technology such as cloud computing. In other words, they prefer the traditional methods of teaching and learning."

The study findings showed that resistance to cloud computing as a new innovation technology negatively affects the adoption of cloud computing in developing countries' universities.

\section{Cost effectiveness}

Cost benefits of cloud computing is a significant factor in this study. All participants agreed that the primary benefit of introducing cloud computing is the cost effectiveness of this technology.

"The Main feature of cloud computing technology, which makes it worthwhile to use is that there is no need to spend upfront costs that are usually supposed to be a heavy investment. For example, in the last five years, our university has initiated three new buildings, and each building costs the university around 90,000\$ for IT infrastructure. If we adopted cloud computing instead, I believe this may avoid this waste in the university budget" (P5).

As a result, the cost-effectiveness of cloud computing is a positive enabler to the addition of this technology in higher educational institutions in developing countries.

\section{Compatibility}

According to the findings from the interviews, the compatibility of cloud computing with current technology is an important factor in cloud technology adoption. The compatibility feature in cloud computing application could be one of the most important enablers of cloud computing at universities. One of the IT technical experts (TE6) stated that:

"Compatibility problem makes a headache for the technical team all the time. For example, the ACAD software can only use inside the institution (intranet) and there is no way to use it outside it. In addition, this system needs a specific configuration on the end user machines that can only work in the specific situation".

Accordingly, cloud computing compatibility with any device as well as the high ability of integration with in-house technology is one of the most important enablers of cloud computing technology.

\section{E. Easy to Use}

The finding of this study showed that stakeholders in universities who took part in this study consider this factor as an enabler of cloud computing adoption. The simplicity of implementing and using cloud computing makes this technology adoption one of the best options for universities in developing countries, as one of the IT managers (TE8) argued that:

"In most cases, the adoption of cloud computing technology is not complicated, except in very rare scenarios when the migration of cloud with in-house technology has a major difference in platforms. Therefore, this simplicity motivated us to accelerate the cloud adoption decision".

Furthermore, one Senior lecturer stated that:

"We have adopted simple educational applications in cloud computing. It is very simple to use with a friendly interface. The students started using it without any technical problems" (P4).

To conclude the above findings, the simplicity of using cloud computing affects the adoption of cloud computing at educational institutions in developing countries. However, there could be difficulties in the migration process, which can usually be handled by cloud service providers and IT staff from the customer side. 


\section{F. Centralization}

One of the cloud computing benefits is its decentralized technology, which makes it usable anywhere, despite the geographical location. Most of the interviewees argued that the centralization of several applications prevented them from providing a better performance and thought that such applications could be accessed only inside the institution using the intranet.

"The centralization of in-house applications is a big challenge for us. For security purposes, we cannot enable the users in our institution to use critical applications through the internet. However, we are studying to transfer these applications to cloud computing. Thus we may improve the performance of lecturers, as they can work outside the institution at any time they prefer" (TE9).

In the same context, one of the senior lecturers added:

"The centralization of using different applications prevents us from traveling all the time. For example, we must stay in the campus in the exam periods because of the examination grading software, which we cannot use outside the university campus".

In brief, the geographical independence in using cloud computing services through the decentralization ability to access technology may be considered as an enabler of cloud computing technology adoption.

\section{G. Management Support}

The final decision of cloud computing adoption needs the top management support. This factor could be neither enabler nor barrier of cloud computing adoption. If the top management is aware of the benefits and limitations of cloud computing this may be an enabler to adopt this technology. Otherwise, the top management might consider such technology useless and then this factor will be a barrier to cloud adoption.

In this context, one of the senior engineers (TE7) declared that:

"Our top management has the power to make the final decision regarding the adoption of cloud computing. However, they are not aware of the technology benefits. Therefore, cloud technology would not be adopted in the near future, unless the top managers learn the excellence of this technology."

As a result, this factor varies from one management to another based on the awareness level of the institution's top management.

\section{H. Knowledge Sharing}

The findings show that cloud computing would positively increase the sharing of knowledge among students. Almost all interviewees agreed that IT, in general, improves the sharing of knowledge. In addition, one of the IT experts argues that the cloud computing concept is based on sharing knowledge as it provides the ability to share content with specific permissions for each user.

"We believe that cloud computing would absolutely improve the level of sharing knowledge. It enables a group of users to share the same applications, content, and services" (TE10).

"Cloud computing applications support both individual and team level services. For example, Google docs, which is a simple application based on cloud technology, enables the user to share the same documents and to edit the same file, providing the full details about each user edition such as time of edit, user permissions, content before and after each user editing, and review sharing mode" (TE6).

To summarise, it is clear that cloud computing technology has the ability to increase the sharing knowledge level among students. Therefore, this factor is considered as an enabler of cloud computing technology adoption at higher education institutions in developing countries.

\section{INTEGRATING DIFFUSION OF INNOVATION THEORY (DOI) WITH CLOUd COMPUTING ADOPTION AT HIGHER EDUCATION INSTITUTION}

DOI theory, developed by Everett Roger [24], [27], [28], has been widely used in innovation adoption studies. The main aim of DOI theory is to help both organizations and individuals, whether in accepting or rejecting innovations [29]. Fig. 2 shows Roger's five steps for adopting an innovation. This study suggested DOI theory for implementing cloud computing technology at higher education institutions. The knowledge, which means awareness, in this study is the first step in adopting cloud computing. The main aim of this step is to increase the awareness level of cloud computing technology benefits and limitations in general.

The second step is to find out the benefits of cloud computing technology in more detail such as compatibility with in-house technology, relative advantages, cost benefits, and increasing sharing knowledge level between students and lecturers behind classrooms. Such step followed by the initial decision regarding the cloud computing adoption at higher education institution. This step may divide to accept the adoption or reject it. There is two type of rejections, the rejection caused by reasons, which may handle by cloud computing serveries providers, and the rejection without any logical reasons based on policies and regulations of any institution. However, this decision still initials based on the reason of rejection and the continuity of accepting or rejecting cloud technology. The fourth step considered the full implementation of cloud technology based on initial acceptance of adoption. Finally, the confirmation of keep using cloud technology for the long term period.

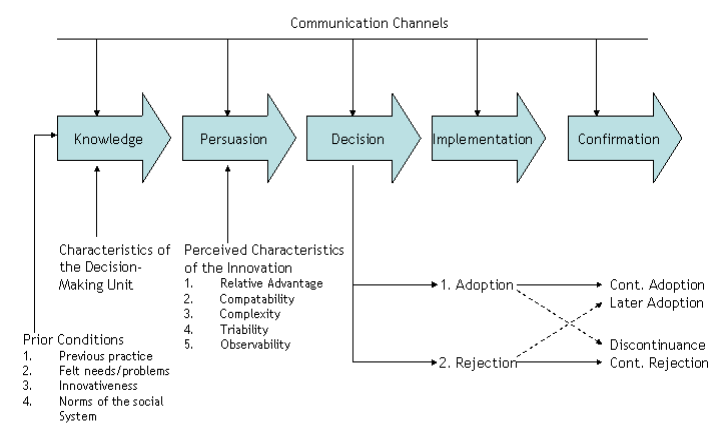

Fig. 2. Innovation-decisions process model [27].

VII. CONCLUSION 
This paper investigates the main factors that affect the adoption of cloud computing at universities in developing countries from both academic and technical perspectives. Semi-structured interviews were conducted with participants including professors in IT and technical experts in IT. Since this study employed an interpretive approach using qualitative methodology, all interviews were recorded after gaining the ethical approval from participants. In addition, the researchers have applied the Nvivo program for transcribing, coding, and finally generating the study's conceptual framework.

The finding suggests that the adoption of cloud computing at educational institutions in developing countries is strongly recommended by academic experts as well as technical professionals. The cloud computing adoption is supported by several enablers such as cost effectiveness, ease of use, improving the level of sharing knowledge, compatibility with devices and software, and geographical decentralization ability to use cloud applications. However, some concerns have arisen as barriers for adopting this technology, such as security and privacy, awareness of top management about this technology's benefits and limitations, compatibility of cloud with in-house technology in case of migration, and resistance to using new technology.

Further research on the adoption of cloud computing may focus on developing a framework for cloud computing adoption at universities in developing countries. Though cloud computing is a new technology, especially in developing nations, further studies in this domain would help academic institutions to understand the benefits, weaknesses, and challenges of adopting this technology.

\section{REFERENCES}

[1] I. Foster, Y. Zhao, I. Raicu, and S. Lu, "Cloud computing and grid computing 360-degree compared," 2008 Grid Computing Environments Workshop, 2008, pp. 1-10.

[2] N. Sultan, "Cloud computing: A democratizing force?" Int. J. Inf. Manage., vol. 33, pp. 810-815, 2013.

[3] Z. Mahmood, Continued Rise of the Cloud. Springer, 2014.

[4] D. C. Chou, "Cloud computing: A value creation model," Computer Standards \& Interfaces, vol. 38, pp. 72-77, 2015.

[5] S. Stein, J. Ware, J. Laboy, and H. E. Schaffer, "Improving K-12 pedagogy via a cloud designed for education," Int. J. Inf. Manage., vol 33, pp. 235-241, 2013.

[6] J. Lian, D. C. Yen, and Y. Wang, "An exploratory study to understand the critical factors affecting the decision to adopt cloud computing in Taiwan hospital," Int. J. Inf. Manage., vol. 34, pp. 28-36, 2014.

[7] A. Lin and N. Chen, "Cloud computing as an innovation: Percepetion, attitude, and adoption," Int. J. Inf. Manage., vol. 32, pp. 533-540, 2012.

[8] K. T. McDonald, Above the Clouds: Managing Risk in the World of Cloud Computing, IT Governance Ltd, 2010.

[9] D. S. Linthicum, Cloud Computing and SOA Convergence in Your Enterprise: A Step-by-Step Guide, Pearson Education, 2009.

[10] M. Armbrust, A. Fox, R. Griffith, A. D. Joseph, R. H. Katz, A. Konwinski, G. Lee, D. A. Patterson, A. Rabkin, and I. Stoica, "Above the clouds: A berkeley view of cloud computing," 2009.

[11] B. Sosinsky, Cloud Computing Bible, John Wiley \& Sons, 2010.

[12] D. Wyld, "Cloud computing 101: Universities are migrating to the cloud for functionality and savings," Computer Sight in Programming Dated, pp. 23-11, 2009

[13] M. Mircea and A. I. Andreescu, "Using cloud computing in higher education: A strategy to improve agility in the current financial crisis," Communications of the IBIMA, 2011.

[14] M. H. Hugos and D. Hulitzky, Business in the Cloud: What Every Business Needs to Know about Cloud Computing, John Wiley \& Sons, 2010.

[15] V. H. Pardeshi, "Cloud computing for higher education institutes: Architecture, strategy and recommendations for effective adaptation," Procedia Economics and Finance, vol. 11, pp. 589-599, 2014.
[16] M. Stieninger, D. Nedbal, W. Wetzlinger, G. Wagner, and M. A Erskine, "Impacts on the organizational adoption of cloud computing: A reconceptualization of influencing factors," Procedia Technology, vol. 16, pp. 85-93, 2014

[17] H. Truong, T. Pham, N. Thoai, and S. Dustdar, "Cloud computing for education and research in developing countries," Cloud Computing for Teaching and Learning: Strategies for Design and Implementation, pp 64-80, 2012

[18] N. Sultan, "Cloud computing for education: A new dawn?" Int. J. Inf. Manage., vol. 30, pp. 109-116, 2010.

[19] F. Shirazi, R. Gholami, and D. A. Higón, "The impact of information and communication technology (ICT), education and regulation on economic freedom in Islamic Middle Eastern countries," Information \& Management, vol. 46, pp. 426-433, 2009.

[20] S. K. Sharma, A. H. Al-Badi, S. M. Govindaluri, and M. H. Al-Kharusi, "Predicting motivators of cloud computing adoption: A developing country perspective," Comput. Hum. Behav., vol. 62, pp. 61-69, 2016.

[21] H. M. Sabi, F. E. Uzoka, K. Langmia, and F. N. Njeh, "Conceptualizing a model for adoption of cloud computing in education," Int. J. Inf. Manage., vol. 36, pp. 183-191, 2016.

[22] S. Greengard, "Cloud computing and developing nations," Commun $A C M$, vol. 53, pp. 18-20, 2010.

[23] B. Scholtz and D. Atukwase, "An analysis of the perceived benefits and drawbacks of cloud ERP systems: A South African study," in Information Technology in Environmental Engineering, Anonymous Springer, 2016, pp. 75-87.

[24] E. M. Rogers, Diffusion of Innovations, New York: Free Press: 2003.

[25] N. Alkhater, G. Wills, and R. Walters, "Factors influencing an organisation's intention to adopt cloud computing in saudi arabia," in Proc 2014 IEEE 6th International Conference on Cloud Computing Technology and Science (CloudCom), 2014, pp. 1040-1044.

[26] L. S. Gilbert, K. Jackson, and S. di Gregorio, "Tools for analyzing qualitative data: The history and relevance of qualitative data analysis software," Handbook of Research on Educational Communication and Technology, Anonymous Springer, 2014, pp. 221-236.

[27] M. Rogers Everett, "Diffusion of innovations," New York, pp. 12, 1995.

[28] E. M. Rogers, Diffusion of Innovations, Simon and Schuster, 2010.

[29] M. H. Fagan, "Global information technology transfer: A framework for analysis," Journal of Global Information Technology Management, vol. 4, pp. 5-26, 2001.

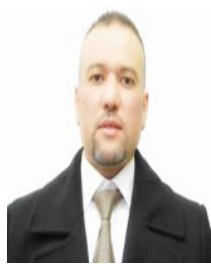

M. Mousa Odeh is currently a $\mathrm{PhD}$ candidate at the Coventry University-Business School. Mahmoud is an international expert engineer in Microsoft and Dell technology. He has gained strong skills in computer virtualization techniques and cloud computing. He also holds more than 10 years' experience with 78 international certificates in project management, computer virtualization, smart machines simulation, and cloud computing. He worked as project manager and gained extensive knowledge through supervised enterprise projects in the field of information technology. His current research and publications are inspired by the rapid evolution of cloud computing technology. Mahmoud is also holding two years academic experience as he taught cloud computing for both undergraduate and postgraduate students.

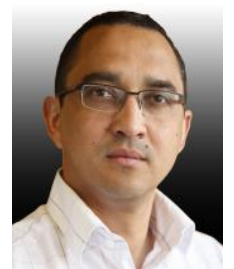

A. Garcia-Perez complemented his original background in computer science (Havana University) with postgraduate studies in information systems up to a doctoral level (Cranfield University, UK).

$\mathrm{He}$ is a reader in cyber security management at Coventry University. There, he leads research on cyber security management, privacy and data-driven innovation at the Centre for Business in Society and is also course director for an MBA in cyber security. Previous roles included information and knowledge management projects for organisations such as Siemens and General Electric. Dr Garcia-Perez is a Senior Fellow of the UK Higher Education Academy and member of the executive committee of the International Association for Knowledge Management.

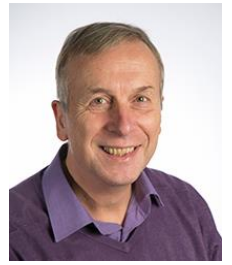

Kevin Warwick is emeritus professor at Reading and Coventry Universities. Prior to that he was deputy vice chancellor (research) at Coventry University, England. His main research areas are artificial intelligence, biomedical systems, robotics and cyborgs. Due to his research as a self-experimenter he is frequently referred to as the world's first Cyborg. Kevin was born in Coventry, UK and left school to join British Telecom. 
He took his first degree at Aston University, followed by a $\mathrm{PhD}$ and research post at Imperial College London. He held positions at Oxford, Newcastle, Warwick and Reading Universities before joining Coventry.

Kevin is a chartered engineer who has published over 600 research papers. His experiments into implant technology led to him being featured as the cover story on the US magazine, 'Wired'. He achieved the world's first direct electronic communication between two human nervous systems, the basis for thought communication. Another project extended human sensory input to include ultrasonics. He also linked his nervous system with the internet in order to control a robot hand directly from his neural signals, across the Atlantic Ocean.

He has been awarded higher doctorates (DSc) by Imperial College and the Czech Academy of Sciences, Prague. Kevin has also been awarded Honorary Doctorates by 8 UK Universities and one from Saints Cyril \& Methodius University, Skopje. He received The IEE Senior Achievement Medal, the IET Mountbatten Medal and the Ellison-Cliffe Medal from the Royal Society of Medicine. In 2000 Kevin presented the Royal Institution Christmas Lectures. 